\title{
Sobre la ambigüedad en un "Nocturno" de Xavier Villaurrutia
}

\author{
José Miguel SARdiÑas*
}

Resumen:

La idea de la poesía de Xavier Villaurrutia como un discurso "construido", poseedor de un riguroso soporte estructural, casi arquitectónico, ha sido recurrente. Sin embargo, eso no significa que sea una poesía rígida, desde ningún punto de vista. Por el contrario, está integrada por textos que añaden, a la oscuridad que en algunos casos tienen, una serie de ambigüedades de carácter sintáctico; textos que, en medio de estructuras generales sintácticamente fijas o determinadas, presentan zonas móviles, con aspectos diferentes según se las mire en una concreción o en otra

$\mathrm{El}$ asunto de este trabajo es justamente el estudios y la revisión de estas zonas móviles, de las estructuras lingüísticas con que se construye la ambigüedad en el "Nocturno en que nada se oye", perteneciente al poemario Nostalgia de la muerte. Del análisis se puede concluir no sólo la posibilidad, textualmente codificada, sino también la necesidad forzosa, ineludible, de leer de varios modos, a veces abiertamente contradictorios, este poema.

\section{Palabras clave:}

Ambigüedad en poesía, Xavier Villaurrutia, "Nocturno en que nada se oye", construcción sintáctica de la ambigüedad, poesía mexicana del siglo XX.

Como señaló Jorge Cuesta antes de que los estructuralistas pusieran de moda el término y antes desde luego de que se conociera en 
Occidente la obra de los formalistas rusos (en particular la de Víktor Shklovski sobre "El principio de construcción"), la poesía de Xavier Villaurrutia posee, entre otros rasgos, el de ser una poesía "construida", 1 el de tener un riguroso soporte estructural, arquitectónico.

Sin embargo, eso no significa que sea una poesía rígida, desde ningún punto de vista. Por el contrario, está integrada por textos que añaden, a la oscuridad que en algunos casos tienen, una serie de ambigüedades de carácter sintáctico; textos que, en medio de estructuras generales sintácticamente fijas o determinadas, presentan zonas móviles, con aspectos diferentes según se las mire en una concreción o en otra. ${ }^{2}$

Estudiar algunas de esas zonas, algunos casos de sentidos o de significados marcadamente ambiguos a partir del nivel sintáctico, es el objetivo de esta comunicación. Doy por sentado el supuesto de que cualquier texto literario -y probablemente también otroses susceptible de ser interpretado o "leído" de maneras diversas, y de que en esa medida cualquier texto es ambiguo. Pero la ambigüedad de la que pretendo ocuparme es de índole menos subjetiva: analizaré casos de lecturas dobles o múltiples originadas por la posibilidad de identificar más de una función sintáctica en los elementos que integran los enunciados, y esto último, a causa de la escansión (de las pausas en los finales de versos y en las cesuras) y de la ausencia de signos de puntuación. ${ }^{3}$

${ }^{1}$ En la nota dedicada a Reflejos, Cuesta decía de la poesía de Villaurrutia: "Esta poesía, construida en función del tacto...” etc. (Antología de la poesía mexicana moderna 223); por otra parte, en un artículo de 1934, "El diablo en la poesía“, llamaba la atención sobre el carácter intelectual de esos textos (Poemas y ensayos 166-171).

${ }^{2}$ Así lo ha visto Merlin H. Forster, aunque no haya extendido sus observaciones al plano del significado de los textos (probablemente porque no fuera ese el objetivo de su obra). Entre las observaciones suyas de que se sirve este trabajo -y que, de hecho, están en su origen- se encuentra la siguiente: "occasionally the lines of demarcation between one pattern and another are blurred, as can be seen in this line in which adjectival complexity is increased by a possibility of at least two readings: 'Ni el duro cristal de dura roca"' (37).

${ }^{3}$ Un caso aparte de ambigüedad lograda por medios lingüísticos es el de los llamados juegos de palabras. En ellos el discurso apela a recursos fónicos para, por medio de un solo signo (lexema, sintagma, oración), y desde luego respaldado por 
Por otra parte, como el estudio de las formas en sí mismas puede constituir un fin, y arrojar un trabajo descriptivo, ${ }^{4}$ creo conveniente además declarar que el de éste es tratar de deducir los sentidos y los matices diferentes que cada posibilidad pueda aportar a una interpretación de los textos, en este caso a la interpretación del "Nocturno en que nada se oye", como ejemplo de lo que sucede en otros poemas de Nostalgia de la muerte (notablemente en el "Nocturno sueño" y en el "Nocturno amor").

El "Nocturno en que nada se oye" trata, en principio, sobre un descenso del sujeto lírico a la muerte. ${ }^{5}$ Así se deduce del encuadramiento inicial, de esos primeros versos en los que traza básicamente circunstancias: su entorno físico y su estado emocional. El sujeto se halla rodeado de un silencio ominoso, que compara con el de una calle donde se va a producir un crimen; es el silencio que precede a la muerte, no el sosiego del retiro, por mencionar uno contrastante.

Se halla, además, en completa soledad; no sólo no está acompañado, sino que siente la ausencia del otro. Es un silencio inquietante

el contexto, pedir varias lecturas de manera simultánea; es el caso de, por ejemplo, "abría las salas", en el "Nocturno sueño", donde, en virtud del proceso de resilabificación o de ruptura de las fronteras silábicas es posible, y necesario además, leer "abría las alas", como ocurre al final del poema. Pero, como ya he dicho, no es este fenómeno, ubicado en el nivel fonológico, el que en este momento me interesa de modo principal. Sobre el concepto de resilabificación, véase una exposición muy sumaria, pero aplicada al español, de entre la ya abundante bibliografía, en James W. Harris (43-44). El ejemplo que menciono se ajusta al fenómeno tal como aquí es descrito: "Resyllabification requires that the second word start with a vowel; final consonants will not link with a nonvowel even though the cluster that would result is permissible within a word" (43).

${ }^{4}$ Como ejemplos de trabajos de este tipo, pueden verse los de César Rodríguez Chicharro: "Disemia y paronomasia en la poesía de Xavier Villaurrutia" y "Correlación y paralelismo en la poesía de Xavier Villaurrutia".

${ }^{5}$ En adelante, siempre que use la palabra sujeto, a no ser que especifique que se trata de un sujeto gramatical, me refiero al agente de la enunciación, a la entidad en la cual se origina el discurso y a la cual pueden adscribirse predicados lógicos, independientemente de la función sintáctica que asuma en el texto. 
y que genera ansiedad. Un silencio que él mismo no interrumpe ni con la respiración, indicio vital por antonomasia. ${ }^{6}$ La subordinada final "para que nada turbe mi muerte" (53) es suficientemente explícita: el sujeto sumido en esos estados supedita su fisiología a la experiencia para la cual se prepara, en un acto de voluntad; reduce sus funciones vitales para entregarse a la muerte.

Y en la elaboración de esa experiencia ${ }^{7}$ es donde la flexibilidad sintáctica puede demostrar su funcionalidad en relación con los significados. Los versos 1 y 2 tienen funciones claras y únicas: ${ }^{8}$ modifican modalmente al verbo "dejar" (v. 5), dicen cómo ocurren las cosas; el sujeto deja su cuerpo -su estatua sin sangre-, en medio de un silencio con las características ya glosadas y apagando la respiración, con el fin mencionado (pues la oración "para que nada turbe mi muerte" se subordina a "respirar"). Sin embargo, el segmento comprendido entre los versos 3 y 5 ofrece varias indeterminaciones. Dicho segmento es el siguiente:

en esta soledad sin paredes

al tiempo que huyeron los ángulos

en la tumba del lecho dejo mi estatua sin sangre (53)

Una posible forma de leerlos es considerar que "en esta soledad sin paredes" se refiere a la manera en que el cuerpo va a ser abandonado

${ }^{6}$ Téngase en cuenta que, por ejemplo, una de las formas de expresar la muerte en el sistema de la lengua es el verbo 'expirar' y que, por otra parte, en la tradición literaria la respiración ha sido símbolo de vida: ya en los poemas homéricos los humanos morían cuando ese soplo - psyché o pneûma- se les escapaba del cuerpo por las fosas nasales.

${ }^{7}$ Uso la expresión con conciencia de lo que significa, por oposición a la actividad poética como registro de experiencias; es decir, que me atengo al poema como realidad válida per se, como experiencia en sí misma, aun cuando no niegue que hay poemas que pueden originarse en una vivencia externa.

${ }^{8}$ Evitaré en lo posible, por lo enfadoso que puede resultar en la lectura, el uso de terminología gramatical; no obstante, en algunos casos ello será difícil, por el tema que he escogido. Mi trabajo, por demás, se efectuará sobre la base del análisis sintáctico tradicional. 
-no en un lugar solitario, sino en condiciones de soledad, de ausencia humana-, que "al tiempo que huyeron los ángulos" funciona como modificador temporal y que "en la tumba del lecho" fija el lugar. Todos serían complementos de la forma verbal 'dejo'. Es decir, el sujeto deja su cuerpo solo, en una soledad definida -ella sípor la ausencia de límites espaciales, de paredes; en la que se puede sentir frente a un espacio vacío y abierto, fuera del ámbito cerrado, y hasta cierto punto protector, de una habitación o de una casa.'

El sujeto, además, deja su cuerpo en ese sitio o en esa forma y sobre el lecho, "al tiempo que huyeron los ángulos". Si, concediéndonos una libertad que sólo tiene valor a los efectos de tantear el poema para analizarlo, le colocamos signos de puntuación, podría parafrasearse: en esta soledad sin paredes, al tiempo que huyeron los ángulos, [...] dejo mi estatua sin sangre. Y habría que entender la soledad ilimitada espacialmente en estrecha relación con la huída de los ángulos. El sujeto no está solo, sino se está quedando solo vertiginosamente; abandona el cuerpo en la soledad que deja la desaparición súbita de las paredes, de las intersecciones que las paredes unidas tienen. Lo curioso -y problemático, desde el punto de vista gramatical- es la correlación entre la perífrasis adverbial "al tiempo que" y el tiempo en que está el verbo "huir".

La frase "al tiempo que" normalmente indica simultaneidad respecto del verbo al cual subordina la oración temporal que introduce. Luego lo normal, una vez más, es que se establezca una correlación temporal entre el verbo de la oración principal y el de la subordinada: al tiempo que huyen los ángulos, dejo mi estatua; o, al tiempo que huían los ángulos, dejaba mi estatua. Porque, además, por la naturaleza de la acción de "huir" se necesita un rasgo gramatical que dé idea de transcurso, que permita entender la huida como un

${ }^{9}$ La soledad sin paredes, sin embargo, podría ser también un lugar, en vez de un modo de abandonar el cuerpo; el énfasis podría ponerse en la lectura de "sin paredes" más que en la de "soledad". Pero esto no modificaría la extensión del sintagma, que de todas maneras quedaría confinado dentro del verso 3; esto no provocaría cambio de sentido por movilidad sintáctica, que es mi tema. 
proceso, aunque sea breve: el aspecto imperfectivo de un presente o de un imperfecto, no la acción puntual de un pretérito ("huyeron"). Sin embargo, lo que ocurre en el poema -o por lo menos en esta lectura- es otra cosa. La correlación se da entre "huyeron" y "dejo".

Como la frase introductoria está imponiendo simultaneidad, es forzoso entonces comprender que la forma en que se abandona el cuerpo es peculiar. La huída de los ángulos, esto es, la desaparición de las paredes y con ello la expansión ilimitada de la sensación de soledad, se muestra a la vez como un proceso y como su final, como un proceso tan veloz que es susceptible de ser concebido y enunciado fundiendo en una palabra los dos momentos: el transcurso y el fin. Y la imagen que esto origina contrasta fuertemente con el modo lento en que el sujeto abandona su cuerpo, pesado y pálido como una estatua yaciente.

La desarticulación de ambas acciones es un primer elemento de vivencia rara, de percepción alienada del medio que rodea al sujeto lírico muriente. Es también el comienzo de una serie de desmembramientos, por medio de los cuales esa entidad va descendiendo a la muerte.

Sin embargo, la anterior no es la única lectura posible del fragmento en cuestión. Otra posibilidad es leer "en esta soledad sin paredes/ al tiempo" como un enunciado coherente, como encabalgamiento, y separarlo de "que huyeron los ángulos", al cual correspondería otra función y otro sentido. En este caso, "en la tumba del lecho" conservaría su rôle de indicador local, de lugar donde se deja la estatua sin sangre.

Antes hemos visto que la soledad sin paredes tiene un carácter modal probable; de hecho, fue la lectura que hice prevalecer. Ahora esa forma de abandonar el cuerpo puede volverse mucho más modal y adquirir una dimensión casi metafísica, si se elige que los límites que la soledad pierde al quedar sin paredes no sean los límites con el espacio, sino los que separan al sujeto solitario del tiempo.

Esto supondría que el sujeto hubiera estado al abrigo de esa dimensión hasta el momento en que las paredes hubieran desaparecido (es decir, dentro), mientras que el tiempo habría estado fuera, y las paredes en medio. Pero no es eso lo que el poema permite 
deducir. El individuo ha estado solo y sin respirar apenas, pero no al margen de la temporalidad. Luego hay que suponer que lo que puede significar esta soledad sin límites con el tiempo es el paso a una dimensión temporal diferente, y eso sí es sostenible a partir del texto, de su ritmo, de su tono. $\mathrm{Al}$ caer las paredes, el agente discursivo siente que pasa a una temporalidad diferente, a esa lentitud de muerte que va dejando como sensación la lectura del poema.

En esta alternativa de lectura, la frase "que huyeron los ángulos" explicaría la causa por la que la soledad ha quedado sin paredes: porque huyeron los ángulos (ya se conoce el valor también causal de la partícula "que" en español). ${ }^{10}$

Una tercera posibilidad de lectura del fragmento se abre cuando, manteniendo "en esta soledad sin paredes" con los valores señalados al principio (modal o local), se lee un nuevo encabalgamiento entre los versos cuarto y quinto: "al tiempo que huyeron los ángulos/ en la tumba del lecho".

Ésta indicaría una desintegración del objeto o lecho-tumba en que el sujeto se abandona. Desmembramiento lógico en la medida en que el sujeto está experimentando una sensación de apertura a lo otro, de transición, que no sólo implica la separación de sí mismo o enajenación, sino también la destrucción de lo que va quedando atrás. Si no hay paredes, si no se respira, si hay silencio o ausencia de sonidos, y muerte o carencia de vida, puede que los ángulos que huyan sean los que constituyen el lecho, y que den lugar a una nueva ausencia o falta: la de forma, de la cama que se desintegra. El sujeto deja su cuerpo sin sangre, al tiempo que los ángulos del lecho han huido. Esta opción no especifica dónde deja el cuerpo, sino privilegia la idea de que lo abandona, de que simplemente lo deja atrás en su marcha. ${ }^{11}$

${ }^{10}$ La predicación implícita que, en este contexto, aflora en el valor semántico de la preposición "sin" (significado de carencia) también posibilita esta lectura. En el sintagma prepositivo "sin paredes" hay una predicación en potencia, y la prueba es que puede conmutarse por otra con verbo explícito como 'que no tiene paredes'. 
En su continuación, el poema va manifestando los signos de la muerte progresiva del sujeto, y llega al conocido y comentado pasaje del juego -angustioso como toda construcción especular-con la voz, que como he dicho no voy a comentar. Sin embargo, su final es una de las zonas funcionalmente ambiguas del texto.

Cuando uno llega a su final encuentra dos símiles que se pueden conectar sin dificultad con la frase que los antecede: "y $\mathrm{mi} \mathrm{voz}$ quema dura/ como el hielo de vidrio/ como el grito de hielo" (53). La idea de quemar es perfectamente compatible con las propiedades del hielo, y un grito puede igualmente quemar, dentro de la lógica poética, mucho más si es un grito que tiene las cualidades del hielo. Al aparecer el verso "aquí en el caracol de la oreja" (53), nada más lógico que atribuirle valor local: mi voz quema, dura, aquí, en mi oreja, y considerar concluido el pasaje. Pero esa es una alternativa; hay otra: "aquí en el caracol de la oreja" puede ser también el lugar donde el sujeto siente el latido de un mar en el que no sabe nada... etc. Es una opción difícil de postular por el hipérbaton que obligaría a leer, que no es ciertamente la norma en los "Nocturnos". Pero gramatical y lógicamente es posible. Por lo que no está de más analizarla, sobre todo teniendo en cuenta que cuanto más se acerca el sujeto a la muerte, más caótica se va volviendo su expresión, y que el hipérbaton podría tomarse como un caso particular de representación del caos en el nivel de la enunciación.

"Aquí en el caracol..." sería entonces, como he dicho, el lugar donde el sujeto siente, y lo sentido sería el latido de un mar que tiene dos modificadores sintácticos: "en el que no sé nada" (53) (de "saber") y "en el que no se nada" (53) (de "nadar"); la subordinada causal del verso 28 ("porque he dejado..." 53) depende de las dos frases anteriores.

El sujeto no sabe nada en ese mar, perdió el conocimiento, porque fue dejando los miembros de su cuerpo en una orilla, porque ya comenzó a alienarse, a experimentar sobre sí los efectos de la división del yo; y en ese mar no se nada, no es posible nadar, por la

${ }^{11}$ En este caso, el sintagma "en la tumba del lecho" deviene complemento de lugar de "huyeron", no de "dejo", como en las lecturas anteriores. 
misma razón, porque no hay miembros con que hacerlo. Lo interesante en esto último es que el sujeto que se está desintegrando parece marcar esa pérdida de su centro al emplear un sujeto gramatical impersonal, de perspectiva imprecisa por excelencia: el "se" de "se nada".

Pero esta última opción de lectura difícilmente podría mantenerse como única cuando uno avanza en el verso 29: "siento caer fuera de mí la red de mis nervios" (54). Si uno había leído "siento" como núcleo verbal del período que le precede, aquí la proximidad de "caer", su significado y la estructura en que parece entrar a formar parte junto con el infinitivo anterior imponen una alternativa nueva: siento que la red de mis nervios cae fuera de mí.

Ahora bien, se trata sólo de una alternativa más, a la postre tan insostenible desde un punto de vista absoluto como la anterior. Pues el texto parece exigir en todo este pasaje dos lecturas simultáneas, para poder producir algún significado.

Ésta es una zona particularmente "blanda", en que la sintaxis se hace laxa, se afloja y origina traslapes. Si se opta por leer sólo "aquí en el caracol de la oreja/ el latido de un mar [...]/ siento", la frase "caer fuera de mí la red de mis nervios" queda en el aire, con un "siento" antecediéndola y prácticamente pidiendo a gritos continuidad discursiva.

Pero si, por el contrario, se opta por leer sólo "siento caer fuera de mí...”, el pasaje anterior se vería forzado de modo verdaderamente violento para resultar inteligible. Habría que entender "el latido de un mar..." como aposición explicativa de la palabra "voz de los versos 18-20 y 22: cae mi voz, y mi voz que madura, etc., como el hielo, etc., aquí, en el caracol de la oreja, mi voz, latido de un mar", etc.; con la dificultad de asignar función apositiva a una frase que comienza con artículo, lo cual sería bastante anómalo, y sólo podría postularse apelando a las circunstancias también anómalas que va construyendo el poema. Un sujeto que va perdiendo su centro, que produce enunciados desde puntos de vista que ya no son el del 'yo', puede también provocar fracturas y "reblandecimientos" en la sintaxis. 
De modo que, considerando poco probable la lección anterior, por lo menos desde el punto de vista que he adoptado para estudiar los "Nocturnos" - pues presupondría abandonar los argumentos sintácticos para sostenerse y recurrir casi como prueba al estado del sujeto-, es preciso recorrer los versos efectuando lecturas inseguras, extendiendo el sentido de una frase o de un período hasta donde las posibilidades de inteligibilidad lo permitan, para luego recortarlas en beneficio de otra que parece reclamar un segmento al que ya habíamos atribuido significado y función. Es preciso entender que la voz del sujeto cae en una prisión de espejos y produce sonidos que se la devuelven con el aspecto de lo absurdo, de la alucinación, del espejismo auditivo. Su voz quema como hielo, dentro de la oreja. Pero inmediatamente "dentro de la oreja" pasa a ser el lugar donde un latido de mar se siente, y donde prácticamente de modo simultáneo lo que se siente es el caer la red de los nervios.

El final del poema es de gran complejidad, desde cualquier punto de vista que se lo mire o estudie. Y el intento de distinguir estructuras formales móviles que permitan sustentar las interpretaciones puede resultar ingrato. No obstante ocurren dos de las que sí se puede hablar con cierto margen de certeza, y de las que de hecho ya ha tratado Merlin H. Forster al analizar brevemente las relaciones entre sonido y significado en varias de las técnicas de Villaurrutia; ${ }^{12}$ hay, además, otro rasgo de sentido que puede ser descrito desde la sintaxis.

La primera de dichas estructuras es "huye todo como el pez que se da cuenta/ hasta ciento...", y la otra, "hasta siento en el pulso de mis sienes/ muda telegrafía a la que nadie responde" (54). ${ }^{13} \mathrm{En}$ la variante en que se lee ciento, la frase "hasta ciento" puede que funcione como complemento circunstancial de cantidad de la

${ }^{12}$ En relación con este pasaje, ejemplificando la técnica que denomina "the forcing of a further dimension in a word in current usage", comenta: "Here the sense of double direction from the same base is produced by counting toward one hundred ('ciento') and at the same time by the pronunciation of the word ('siento') which moves the image toward a telegraphic system which no one answers" (67).

${ }^{13}$ Podría argüírseme que me estoy valiendo más que de dos lecturas, de dos lecciones, de dos variantes textuales, y que quien leyera el poema en una sola de ellas 
perífrasis verbal "darse cuenta". El sujeto ha ido perdiendo partes de su ser, ha terminado por ver caer fuera de sí incluso lo que le permite percibir sensorialmente el mundo, sus nervios, y a estas alturas de su viaje a la muerte ya las ideas le proceden por analogías que hacen pensar en cierto automatismo. Como ha sentido que los nervios se le escapan en forma de red, como esa imagen ha surgido en medio de otras imágenes acuáticas como mar, orilla, caracol y nadar, ahora describe asociativamente la dispersión total del yo físico como una huida de todo, asimilable a la de un animal de las aguas: un pez, y un pez que se da cuenta, en una medida muy alta, de algo que el texto no llega a enunciar (acaso, y lógicamente, de algún peligro). La cifra puede indicar, a modo de número determinado usado para dar idea de cantidad indeterminada pero muy grande, el espanto, la velocidad de la huida del animal, y por medio de ella la forma en que se realiza la disgregación del físico del sujeto.

La variante que muestra "siento", que es no sólo la más legible sino también la más acertada -la anterior puede resultar funcional y hasta acercar el poema a los textos surrealistas, pero independientemente de que ello no es un mérito per se, la imagen a que da lugar tiene el aspecto de lo forzado-, se explica desde la perspectiva lingüística como una oración independiente, "siento en el pulso de mis sienes muda telegrafía...", con otra que se le subordina para ampliar su sentido: “...a la que nadie responde”. Está precedida por la preposición "hasta", en este caso con valor ponderativo, marcando

no podría tener en cuenta la otra. Pero lo cierto es que el poema es uno, que estudiarlo es una cosa y otra es leerlo, y que las diferencias entre las ediciones, además, no son tan grandes como para considerar que se trate de dos versiones, sino de la misma obra, con un solo cambio. Por tanto dicha obra tiene que incorporar la lección en que la palabra [siento] aparece con la grafía ese tanto como la lección en que aparece con ce. Porque, por otra parte, ambas parecen obedecer a la voluntad-lúdicra-del autor. De este "Nocturno" se hicieron, en vida de Villaurrutia, tres ediciones, y en unas la palabra adopta una grafía (cien, ciento), y en otras, la otra (siento). De modo que ambas parecen llevar el juego con la forma de los textos a ese plano mayor que es la variante entre ediciones, y en consecuencia pueden ser tomadas en cuenta para estudiar las zonas móviles a que en cada caso den lugar. El asunto está bien resumido y expuesto en Eugene L. Moretta (168, nota 29). 
un grado superior de lo que el sujeto siente, y relacionada de este modo con la expresión similar del verso 29 , en una de sus posibles lecturas: "siento caer..."

El sujeto no sólo siente desfallecimiento al perder el contacto sensorial con el mundo, sino -más aún- que sus sienes de hombre solitario envían señales que nadie responde. Podría parecer contradictorio el que, después de haberse desvinculado del exterior, conserve algo somático como las sienes, pero eso no entra en desacuerdo con cierta marcha que el poema ha descrito. Ha ocurrido la separación de lo menos esencial al sujeto: los miembros, la voz, la sensibilidad; finalmente queda reducido al órgano en que suponemos que radica lo más definitorio de nuestras personalidades: el cerebro.

El rasgo de sentido del cual he dicho antes que se afinca en la sintaxis es el debilitamiento del valor de nexos como el adversativo "mas" y el causal "porque". En efecto, al final del descenso a la muerte, en un momento en que el sujeto ya se ha desprendido de todo, acaba por perder la facultad de usar el lenguaje con toda lógica, y contrapone ideas entre las cuales no hay oposición como la de que sienta caer fuera de sí sus nervios y la de que todo huya, que más bien se relacionan, o enlazando causalmente otras entre las cuales resulta realmente difícil descubrir un vínculo de ese tipo, como sería la de que nadie responda la muda telegrafía de sus sienes y la de que eso ocurra porque el sueño y la muerte no tengan ya nada que decirse. ¿Acaso tuvieron algo que decirse antes? -pregunta que surge de la presencia del adverbio "ya". ¿Qué relación puede haber entre el hecho de emitir señales que nadie responda y el que el sueño y la muerte sean dos entidades mudas?

La aparición del sueño en este momento del poema obliga a releer todo lo anterior como una posibilidad de descenso a ese estado, y no a la muerte únicamente; tal vez, más bien, como la posibilidad de descenso a ambas cosas: a un estado de sopor mortal o letal, con lo cual las lecturas propuestas anteriormente se multiplicarían (atormentadoramente) en varias direcciones. No obstante, no es preciso emprender semejante tarea ahora. Con lo observado y analizado basta para concluir afirmando no sólo la posibilidad, textualmente codificada, sino también la necesidad forzosa, ineludible, 
de leer de varios modos, a veces abiertamente contradictorios, este poema. Las zonas de él anteriormente analizadas son una forma de no sólo indicar o describir verbalmente el proceso de pérdida y desintegración del sujeto lírico en su tránsito a una muerte, sino también de ir demostrándolo en el propio nivel lingüístico o, lo que es igual, de convertirlo en una especie de excelente y compleja performance de su propia predicación.

\section{Obras citadas}

Cuesta, Jorge. Antologia de la poesía mexicana moderna. México: Fondo de Cultura Económica, 1985.

. "El diablo en la poesía." En su libro Poemas y ensayos. Eds. Miguel Capistrán y Luis Mario Schneider. México: UNAM, 1978, t. 2. 166-171.

Forster, Merlin H. Fire and Ice: the Poetry of Xavier Vilaurrutia. Chapel Hill: North Carolina Studies in the Romance Languages and Literatures, 1976.

Harris, James W. Syllable Structure and Stress in Spanish. A Nonlinear Analysis. Cambridge (Mass.): The Massachusetts Institute of Technology Press, 1983.

Moretta, Eugene L. La poesía de Xavier Villaurrutia. México: Fondo de Cultura Económica, 1976.

Rodríguez Chicharro, César. "Disemia y paronomasia en la poesía de Xavier Villaurrutia." La Palabra y el Hombre 8 (1964): 249260.

. "Correlación y paralelismo en la poesía de Xavier Villaurrutia." La Palabra y el Hombre 10 (1966): 81-90.

Villaurrutia, Xavier. Nostalgia de la muerte (Poemas y teatro). 2a. ed. México: Fondo de Cultura Económica/Secretaría de Educación Pública, 1984. 